\title{
Discussion on Measurement and Optimal Management Technology of Forest Based on Visual Identity
}

\author{
Rui Pan and Jidong Ma \\ Harbin institute 1, Northeast forestry university 2, Heilongjiang, Harbin, 150086
}

\begin{abstract}
Nowadays, there are increasingly obvious contradictions between the wood production and the rapid development of national economy. In addition, there are wild work, extensive management and astonishing waste in the forestry production and management field. The major work for the forestry workers of China at present is how to provide woods with high quality faster and better and how to manage the forests more reasonably.
\end{abstract}

Keywords-visual identity; forest measurement; optimal management technology

\section{INTRODUCTION}

Forest management means to change the forest, and the most prominent feature of the process is the irreversibility. It plays the decisive role in the future growth of the forests and has a great influence on the growth and development and the harvest of the woods once the forest manager makes the management decisions and brings them into force. So it is much more important to the forest managers to make the scientific management strategies. It is obvious a good solution in solving this problem to replace the implement of practical management measures with virtual methods of system simulation in assisting the management decision making. What's more, there are two more significant features of the research on forestry than other subjects: long time span and large space, great working difficulty and long duration of effect. It is the two significant features that make the forestry research be faced with great difficulties. As a result, it needs to bring a technology which can describe and analyze the forestry information accurately, reliably and vividly to the forest management. It is always the dream of forestry scholars to use the virtual reality technology and system simulation technology to do visual simulation of the forest.

\section{Purpose AND SignificAnCE OF THE ProJeCt RESEARCH}

The research on natural management technology and forest measurement based on visual identity is guided by close-to-nature management theory and is targeted by analyzing and comparing the influences on the forest of different management measures. It takes the rapid and accurate measurement on forest as means and is featured by replaying the growth and development law of forest in real time and predicting the forest's growing conditions in different periods. The research can also use the optimal methods of wood measurement, wood cracking and wood making of raw materials and set rational density of forestry net to do dynamic simulation analysis of the forestry management. We can get the optimal production plan and make the optimal forest management scheme based on this which provides the most basic and authorized data for the value assessment and rational development of the forest. This research will enhance the forest management standard of our province greatly, strengthen the protection of forest resources, decrease the unnecessary man-made disturbance to the forest and will play a vital function in the sustainable development of the forest.

\section{Key TECHNICAL CONTENTS AND TECHNICAL INNOVATIONS OF THE PROJECT}

\section{A. Research Target}

Taking the main commercial forest in Lesser Khingan Mountains as the target and through the research, we seek for the rapid, effective and accurate measurement technologies aiming at all components (trunk, branch and crown) of the woods, build the wood succession and prediction model under specific site conditions and develop the optimal design software of forest management scheme. Through the analogue simulation, we establish the accurate management system model, put forward the optimal management pattern fitting for the Lesser Khingan Mountains and provide scientific support and example for enhancing whole standard of forest management, playing the ecologic function of the forest and promoting the sustainable development of our country's forestry and forest economy and society.

\section{B. Key Technical Contents}

(1) Forest accurate measurement technology. Do the tree measurement factor investigation on the typical forests of Lesser Khingan Mountains by using the computer visual identity technology on the divided temporary sample plot and permanent sample plot, and do the comparison and analysis with the traditional measurement methods, and then put forward the forest accurate measurement technology.

(2) Forest succession and prediction model. Based on the stand structure law and forest competition rule, we establish the forest succession and prediction model under specific site condition in the data mining method by analyzing all the tree measurement factors in permanent sample plot and the historical data of second class and third class investigation of forest resources.

(3) Optimal design of forest management simulation and 
management project. Based on raw data, we build virtual forest scene by using computer programming technology and image processing technology to determine the dominant tree species (target tree). Based on the scene, we can simulate the main production and management measures, such as forest main felling regeneration, forest tending felling, artificial pruning and stand conversion, etc., and can analyze the influence condition of the management activities on all the forest indicators (stumpage coverage, forest horizontal distribution pattern, competition, species composition and diameter distribution, etc). We can design the optimal management project to realize the close-to-nature forest management characterized by individual tending and selective felling by using the optimal theory of whole trunk wood measurement and making and forest net.

(4) Establishment of accurate management model. Through the test and research in different foreststands, we choose the management technologies and model fitting for the typical forest of Lesser Khingan Mountains, establish the accurate management system and build the trial demonstration area.

\section{Technical Innovations}

(1) Put forward the forest accurate measurement technology.

(2) Build the accurate management system in forest industry combining with forestry measures.

IV. STAtUs of RELATIVE INDUSTRY IN DOMESTIC, DEVELOPMENT TENDENCY, MARKET DEMAND AND ANALYSIS OF EXPECTED ECONOMIC AND SOCIAL BENEFITS

\section{Status of Relative Industry in Domestic and Development Tendency}

We can see from the research aspect of forest management that China started late in this. In the middle of 1950s, China implemented the forest working plan, the contents of which were greatly affected by the traditional forestry model of the former Soviet Union. The forest management in about 1960s and 1970s focused on the large area forest development . The forest management was replaced by production and felling, and formed the triune development fever by Forest Industry Bureau. The legal status of the forest management work was determined until the Forest Law was published in 1985, which promoted the management work of the forestry. Since the reform and opening up, dominated by Northeast Forestry University, Heilongjiang Academy of Forestry and Liaoning Forestry Institution in the Northeast China and dominated by China Forestry Institution in Northwest China, people have done some research work related to the forestry management, such as management theory, growth prediction, stand conversion, resource measurement and tending felling, etc., which has laid an important foundation for the future research on the forest management.

After the suffering and exploration, the foreign research on forest management has established the close-to-nature management theory and technical system characterized by individual tending represented by Germany. It has been put into use in Switzerland, Norway, Belgium, Netherlands,
Austria and France, etc. and has gained initial achievements. In the aspect of the technical means of forest management, it has brought the computer technology, analogue simulation technology, digital photogrammetry technology and remote sensing technology to the forest management. The investigation of foreign forest resource mainly uses the aerial photo in medium scale to estimate or measure the characters of stand in the three-dimensional aerial photos and to form the stock map. The traditional ground investigation is gradually replaced by the aerial photo investigation in large scale especially in the USA. The related research on forest growth, modeling and $3 \mathrm{D}$ visualization virtual management mainly concerns how to display the forests and how to predict the forest growth scientifically. The research includes the tree architecture, simulation study on trees growth and calculation of displaying the forests, etc.

\section{E. Market Demand and Analysis of Expected Economic and Social Benefits}

The forest ecological system changes slowly with a long updating circle, and the change of the forest is irreversible. The regular tests or statistic methods of researching the forest growth rule and management effects usually take a long time, and it is a waste of human resources and money. What's more, the forest management is a large system with the characteristics of multilevel, multiple targets, multiple means and multiple factors with large risk. Human are not qualified for it. However, taking computer as the tool, the application of the system's principle and methods can not only reflect the whole process of forest management quantitatively, visually and in real time, but also can get the optimal solution. Based on the close-to-nature theory of forest management, the implement of the project can realize the efficient utilization of the forest resource, and can enhance the maximum average growth of the high valued trees (target trees). It also can make every tress have its own function and mature utilization time to realize the sustainable use of the forest by the purpose accurate working to the target trees. All in all, the project has good economic benefit, social benefit and ecological benefit.

\section{RESEARCH TECHNOLOGY AND PROCESS}

The expected indicator of the project is to put forward the forest accurate measurement technology, to establish the forest succession and prediction model, to research the optimal design software of forest management project, to put forward one or two optimal management patterns for the typical stand of Larger and Lesser Khingan Mountains, to make the volume of forest tree growth increase by $5 \%$ to $10 \%$ and to make the forest utilization rate increase by $4 \%$ to $8 \%$.

\section{ACKNOWLEDGMENT}

Fund project: study abroad returnees science fund project in heilongjiang province "Research on Optimal Management Technology and Forest Measurement Based on Visual Identity”, Item number: LC2011C39;Subproject of special scientific research in forest public industry: Research on forest accurate management technology for Greater and Lesser Khingan Mountains and research on forest accurate management software, Item number: 201204509 


\section{REFERENCES}

[1] Song Xiaochun, Chinese Higher Engineering Education and Cultivation of Engineers, Computer Engineering and Deign, Page 22-25, May 2005

[2] Guo Xiurong, Automatic Measurement Technology of Volume of Wood Based on Laser Scanning, Forest Sciences, Page 31-33, September 2008

[3] Hou Xinxin, Research on Wood Image Identification System Based on CCD and Theodolite, December 2014

[4] Hu Tianxiang, Wood Image Location Method Based on Binocular Vision, Transactions of the Chinese Society for Agricultural Machinery, November 2010 